\title{
Loss of the normal coupling between the anaerobic threshold and insulin sensitivity in chronic heart failure
}

F Leyva, T-P Chua, I F Godsland, A J S Coats, S D Anker

\begin{abstract}
Objective-To explore whether the anaerobic threshold, a measure of the balance between aerobic and anaerobic cellular metabolism, is related to whole body insulin sensitivity in healthy individuals and in patients with chronic heart failure, which involves is an imbalance of aerobic and anaerobic metabolism.

Design-Case-control study.

Setting-A teaching hospital department specialising in heart failure.

Patients-20 healthy individuals (mean (SEM) age $55.2(2.7)$ years) and 36 patients with chronic heart failure (59.1 (2.0) years, New York Heart Association class I-IV, anaerobic threshold $11.8(0.7)$ $\mathrm{ml} / \mathrm{kg} / \mathrm{min}$, left ventricular ejection fraction 26 (2)\%).
\end{abstract}

Interventions-An intravenous glucose tolerance test for assessment of insulin sensitivity (minimal model analysis) and a maximum treadmill exercise test for assessment of the anaerobic threshold, derived from measurement of oxygen consumption and carbon dioxide output.

Main outcome measures-Relation between insulin sensitivity and the anaerobic threshold in patients with chronic heart failure.

Department of Cardiac Medicine, Imperial College School of Medicine at the National Heart and Lung Institute, London SW3, UK

F Leyva

T-P Chua

A J S Coats

$S$ D Anker

The Rosen

Laboratories of the

Wynn Institute,

Endocrinology and

Metabolism, Imperial

College School of

Medicine, St Mary's

Campus, London W2,

UK

I F Godsland

Correspondence to: Dr Francisco Leyva,

Department of Cardiology,

Royal Brompton Hospital,

Sydney Street, London

SW3 9NP, UK.

email: leyvaleon@

hotmail.com

Accepted for publication 18 March 1999
Results-While anaerobic threshold was positively correlated with insulin sensitivity in healthy controls $(r=0.72$, p $<0.001$, no such relation was observed in patients with chronic heart failure. In stepwise multiple linear regression analyses of variables in healthy individuals, insulin sensitivity emerged as the only predictor of anaerobic threshold (standardised coefficient $=0.72, p<0.001)$, while fasting insulin, incremental insulin area, and total body fat (dual photon $x$ ray absorptiometry) failed to enter into final models (joint $R=0.52, \mathrm{p}<0.001$ ).

Conclusions-In healthy individuals, whole body insulin sensitivity is related, or "coupled," to the anaerobic threshold. The absence of such metabolic coupling in patients with chronic heart failure provides further evidence of disturbed cellular metabolism in patients with this condition.

(Heart 1999;82:348-351)

Keywords: heart failure; anaerobic threshold; insulin resistance
The cellular supply of energy in the form of high energy phosphates relies on a balance between glycolysis (mainly anaerobic) and the citric acid cycle (aerobic). As well as requiring glucose and oxygen, the generation of glycolytic intermediates also requires insulin. This hormone not only drives cellular uptake of glucose, but also exerts a regulatory influence on glycolytic enzymes. ${ }^{1-3}$ Thus cellular metabolism requires coordination or "coupling" between the cellular processing of glucose and oxygen and insulin action.

On the basis of the above, we considered that whole body measures of the anaerobic threshold, which reflects the balance between aerobic and anaerobic metabolism, might relate to whole body insulin sensitivity. Our investigation focuses on healthy individuals and on patients with chronic heart failure - an insulin resistant state ${ }^{4}$ in which there is an imbalance between oxidative and non-oxidative metabolism. . $^{5-8}$

\section{Methods}

The study group consisted of 36 patients with chronic heart failure caused by coronary heart disease (19) or dilated cardiomyopathy (17). The diagnosis of chronic heart failure was based on standard criteria. All patients had been in heart failure for at least six months before the study. Concurrent treatment in the heart failure group included angiotensin converting enzyme inhibitors, loop diuretics, digoxin, warfarin, nitrates, amiodarone, and thiazide diuretics, either alone or in combination. No patients were taking hypouricaemic drugs. Healthy controls were matched for age and sex and were free from cardiovascular disease, on the basis of clinical history and examination and routine investigations. All patients gave written, informed consent and the study was approved by the local ethics committee.

\section{ANAEROBIC THRESHOLD}

During cardiopulmonary exercise testing, all patients were exercised to exhaustion (respiratory exchange ratio $>1.1$ ). A one way valve connected to a respiratory spectrometer (Amis 2000, Odense, Denmark) was employed. Oxygen consumption was calculated on-line using a standard inert gas dilution technique..$^{9}$ The slope of the regression line relating minute ventilation to carbon dioxide output was employed as an index of the ventilatory response to exercise. ${ }^{11}$ These measures were obtained during a maximum exercise test, using a modified Bruce protocol for patients with chronic heart failure. 
Table 1 Characteristics of the study and control groups

\begin{tabular}{|c|c|c|c|}
\hline Variable & Healthy controls $(n=20)$ & CHF patients $(n=36)$ & $p$ Value ${ }^{\star}$ \\
\hline Age (years) & $55.2(2.7)$ & $59.1(2.0)$ & NS \\
\hline Body mass index $\left(\mathrm{kg} / \mathrm{m}^{2}\right)$ & $28.2(1.1)$ & $25.6(0.7)$ & NS \\
\hline Total body fat (kg) & $22.3(1.8)$ & $18.7(1.2)$ & NS \\
\hline LV ejection fraction (\%) & ND & $25.6(2.3)$ & - \\
\hline Systolic blood pressure (mm Hg) & $126.0(3.1)$ & $111.8(2.8)$ & 0.002 \\
\hline Diastolic blood pressure $(\mathrm{mm} \mathrm{Hg})$ & $79.4(2.4)$ & $70.0(1.6)$ & 0.001 \\
\hline \multicolumn{4}{|l|}{ NYHA class $(\mathrm{n})$} \\
\hline I & - & 4 & \\
\hline II & - & 11 & \\
\hline III & - & 18 & \\
\hline IV & _- & 3 & \\
\hline Fasting glucose $(\mathrm{mmol} / \mathrm{l})$ & $5.4(0.1)$ & $5.7(0.3)$ & NS \\
\hline Fasting insulin $(\mathrm{pmol} / \mathrm{l})$ & $53.3(-7.7,+9.0)$ & $56.6(-6.6,+7.5)$ & NS \\
\hline Incremental glucose area (mmol/1.min) & $631.5(127.1)$ & $539.3(35.1)$ & NS \\
\hline Incremental insulin area $\left(10^{4} \cdot[\mathrm{pmol} / 1] \cdot \mathrm{min}\right)^{\star} \dagger$ & $2.52(-0.25,+0.27)$ & $2.02(-0.27,+0.29)$ & NS \\
\hline Insulin sensitivity $\left(10^{5} / \mathrm{min} /[\mathrm{pmol} / 1]\right) \neq$ & $3.33(-0.61,+0.67)$ & $2.02(-0.27,+0.29)$ & 0.035 \\
\hline Anaerobic threshold $(\mathrm{ml} / \mathrm{kg} / \mathrm{min})$ & $16.8(1.0)$ & $11.8(0.7)$ & $<0.001$ \\
\hline
\end{tabular}

Values are mean (SEM) unless otherwise stated.

$\star$ Differences between groups from analysis of variance; $\nmid \log$ transformed for statistical analysis; $\ddagger$ square root transformed for statistical analysis.

CHF, chronic heart failure; LV, left ventricular; ND, not done; NYHA, New York Heart Association.

The ventilatory anaerobic threshold was calculated according to the technique of Beaver et $a l .{ }^{12}$ Briefly, the anaerobic threshold is selected as the oxygen consumption $\left(\mathrm{V}_{2}\right)$ at which the slope of the carbon dioxide output $\left(\dot{\mathrm{V}} \mathrm{CO}_{2}\right)$ versus $\dot{\mathrm{V}}_{2}$ changes from 1 or slightly less than 1 to a slope which is steeper than 1 . The intersection of these slopes is taken as the $\dot{\mathrm{V}}_{2}$ above which the increased $\dot{\mathrm{VCO}}_{2}$ can only be explained by the increase in metabolic acidosis.

\section{INSULIN SENSITIVITY}

Participants underwent an intravenous glucose tolerance test with sampling at 16 time points during 180 minutes, as previously described. ${ }^{13}$ Dextrose was given intravenously as a $50 \%$ solution, at a dose of $0.5 \mathrm{~g} / \mathrm{kg}$ body weight. Plasma glucose was determined on the same day using glucose oxidase procedures. ${ }^{14}$ Plasma insulin concentrations were measured on samples stored at $-20^{\circ} \mathrm{C}$ using a radioimmunoassay procedure..$^{15}$ Insulin sensitivity, inversely related to insulin resistance, was assessed using the minimal model approach. ${ }^{16}$

\section{BODY FAT COMPOSITION}

Height $(\mathrm{m})$ and weight $(\mathrm{kg})$ were determined to calculate body mass index (BMI: weight/ height ${ }^{2}$ ). Total fat mass was estimated by dual energy $x$ ray absorptiometry (DXA) using a Lunar DPX (Lunar Corporation, Madison, Wisconsin, USA). ${ }^{17}$ All scans were performed and analysed using version $3.6 \mathrm{z}$ software. Precision of fat tissue measurements was better than $5 \% .^{18}$

Table 2 Univariate Pearson correlation analysis of anaerobic threshold against metabolic variables in healthy individuals and in patients with chronic heart failure (CHF)

\begin{tabular}{lcl}
\hline Variable & $\begin{array}{c}\text { Controls } \\
(n=20)\end{array}$ & $\begin{array}{l}\text { CHF } \\
(n=36)\end{array}$ \\
\hline Fasting glucose & -0.37 & -0.08 \\
Fasting insulin & $-0.49^{\star}$ & -0.03 \\
Incremental glucose area & 0.18 & -0.04 \\
Incremental insulin area & $-0.64^{\star \star}$ & 0.23 \\
Insulin sensitivity & $0.72^{\star \star \star}$ & -0.12 \\
Total body fat & -0.28 & 0.15 \\
\hline
\end{tabular}

${ }^{\star} \mathrm{p}<0.05 ;{ }^{\star \star} \mathrm{p}<0.01 ;{ }^{\star \star \star} \mathrm{p}<0.001$
STATISTICAL ANALYSES

These were carried out using the SYSTAT statistical package (SYSTAT Inc, Evanston, Illinois, USA). Univariate Pearson correlation coefficients were derived. A general linear model was used in multivariate analyses of pooled subjects. In all analyses, a $p$ value of $<0.05$ was considered statistically significant.

\section{Results}

As shown in table 1, the chronic heart failure group had a lower insulin sensitivity $(p=0.035)$ and anaerobic threshold $(\mathrm{p}<0.001)$ as well as lower systolic $(p=0.002)$ and diastolic $(\mathrm{p}=0.001)$ blood pressures.

Univariate analyses of variables in healthy individuals revealed a significant correlation between anaerobic threshold and insulin
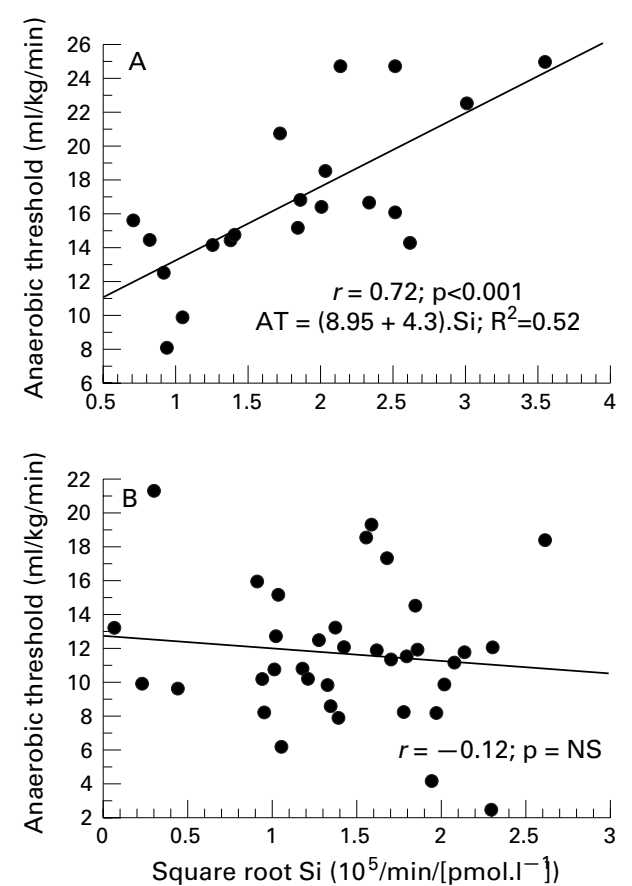

Figure 1 Regression scatterplots of insulin sensitivity (Si) against anaerobic threshold (AT) in (A) healthy individuals, and (B) patients with chronic heart failure. $r$, Pearson correlation coefficient. 
sensitivity, incremental insulin area, and fasting insulin (table 2). In contrast, no significant correlations were observed in the chronic heart failure group (fig 1).

Variables which were found to be correlated in univariate analyses were entered in multivariate analyses. In stepwise multiple linear regression analyses of variables in healthy individuals, insulin sensitivity emerged as the only predictor of anaerobic threshold (standardised coefficient $=0.72, \mathrm{p}<0.001$ ), while fasting insulin, incremental insulin area, and total body fat failed to enter into final models (joint $R=0.52, \mathrm{p}<0.001)$.

\section{Discussion}

We have shown that in healthy individuals, there is a strong relation between the anaerobic threshold and insulin sensitivity. This relation might be expected in view of the coordination that exists between oxygen and glucose uptake at the cellular level. A salient finding from this study is that the relation between the anaerobic threshold and insulin sensitivity observed in healthy individuals is absent in patients with chronic heart failure.

Our demonstration of a lower anaerobic threshold in patients with chronic heart failure is in keeping with the finding of an early switch to anaerobic metabolism in this condition, as evidenced by a rapid rise in blood lactate levels during exercise. ${ }^{6719}$ In contrast to our findings in healthy individuals, we found that in patients with chronic heart failure, reductions in insulin sensitivity are not accompanied by commensurate reductions in the anaerobic threshold. This suggests that the coupling between glucose and oxygen metabolism and insulin action that occurs in healthy individuals is disturbed in chronic heart failure.

Several factors may be responsible for the lack of this relation.

First, it is recognised that insulin may, by causing vasodilatation, promote its own transport into skeletal muscle - the principal site of insulin action. ${ }^{20}$ On the other hand, insulin mediated vasodilatation is impaired in states of insulin resistance. ${ }^{20}$ Thus the impairment in peripheral vascular responses observed in patients with chronic heart failure ${ }^{21-24}$ might not only lead to variation in the tissue availability of oxygen but also in the delivery of insulin to skeletal muscle. This could be responsible for the loss of a relation between insulin sensitivity and the anaerobic threshold.

Second, chronic heart failure involves disturbances in oxidative and lipolytic enzymes as well as in skeletal muscle fibre distribution and mitochondrial structure, ${ }^{25}$ which could contribute to disturbances in the tissue responsiveness to insulin.

Third, defective post-receptor insulin signalling, arising from reductions in the glucose transporter protein GLUT-4 found in the myocardium of patients with heart failure, ${ }^{26}$ may also contribute to tissue responsiveness to insulin.
We conclude that whereas in healthy individuals, the anaerobic threshold is positively related to insulin sensitivity, this relation is absent in patients with chronic heart failure. This observation is in keeping with the known mechanisms that link oxygen and glucose metabolism and insulin action at the cellular level. On the basis of our findings, disturbances in cellular metabolism that occur in heart failure, such as a low anaerobic threshold, do not appear to be related to reductions in insulin sensitivity. Further studies are needed to determine which additional factors are responsible for the "uncoupling" of glycolysis and insulin mediated glucose uptake in patients with chronic heart failure.

FL and IFG were supported by the Heart Disease and Diabetes Research Trust and by the Rosen Foundation.

1 Alexander MC, Lomanto M, Nasrin N, et al. Insulin stimulates glyceraldehyde-3-phosphate dehydrogenase gene expression through cis-acting DNA sequences. Proc Natl Acad Sci USA 1988;85:5092-6.

2 Alexander M, Curtis G, Avruch J, et al. Insulin regulation of protein biosynthesis in differentiated $3 \mathrm{~T} 3$ adipocytes. Regulation of glyceraldehyde-3-phosphate dehydrogenase. F Biol Chem 1985;260:11978-85.

3 Alexander-Bridges M, Ercolani L, King XF, et al. IdentificaAlexander-Bridges $\mathrm{M}$, Ercolani L, King XF, et al. Identifica-
tion of a core motif that is recognised by three members of tion of a core motif that is recognised by three members of
the HMG class of transcriptional regulators. $\mathcal{F}$ Cell Biochem 1992;48:129-35.

4 Swan JW, Anker SD, Walton C, et al. Insulin resistance in chronic heart failure: relation to severity and etiology of heart failure. 7 Am Coll Cardiol 1997;30:527-32.

5 Drexler H, Riede U, Munzel T, et al. Alterations of skeletal muscle in chronic heart failure. Circulation 1992;85:17519.

6 Donald KW, Gloster J, Harris EA, et al. The production of lactic acid during exercise in normal subjects and patients with rheumatic heart disease. Am Heart $\mathcal{F}$ 1961;62:494510 .

7 Huckabee WK, Judson WE. The role of anaerobic metabolism in the performance of mild muscular work. I. and the effect of congestive cardiac failure. 7 Clin Invest $1958 ; 37: 1577-92$.

8 Wilson JR, Martin JL, Schwartz D, et al. Exercise intolerance in patients with chronic heart failure. Role of intolerance in patients with chronic heart failure. Role of 69:1079-87.

9 Lipkin DP, Perrins J, Poole-Wilson PA. Respiratory gas exchange in the assessment of patients with impaired ventricular function. Br Heart f 1985;54:321-8.

10 Davies N, Denison DM. The measurement of metabolic gas exchange and minute volume by mass spectroscopy alone. Resp Physiol 1979;36:261-7.

11 Buller NP, Poole-Wilson PA. Mechanism of the increased ventilatory response to exercise in patients with chronic heart failure. Br Heart f 1990;63:281-3.

12 Beaver WL, Wasserman K, Whipp BJ. A new method for detecting the anaerobic threshold by gas exchange. $7 \mathrm{Appl}$ Physiol 1986;60:2020-7.

13 Swan JW, Walton C, Godsland IF, et al. Insulin resistance in heart failure. Eur Heart f 1994;15:1528-32.

14 Trinder P. Determination of blood glucose using an oxidase-peroxidase system with non-carcinogenic chromogen. F Clin Pathol 1969;22:158-61.

15 Albano JDM, Ekins RP, Maritz G, et al. A sensitive, precise radioimmunoassay of serum insulin relying on charcoal radioimmunoassay of serum insulin relying on charcoal
separation of bound and free hormone moieties. Acta separation of bound and frec

16 Godsland IF, Crook D, Walton C, et al. Influence of insulin resistance, secretion, and clearance on serum cholesterol, triglycerides, lipoprotein cholesterol, and blood pressure in healthy men. Arterioscler Thromb 1992;12:1030-5.

17 Mazess RB, Barden HS, Bisek JP, et al. Dual-energy x-ray absorptiometry for total-body and regional bone-mineral and soft-tissue composition. Am F Clin Nutr 1990;51:110612.

18 Ley CJ, Lees B, Stevenson JC. Sex- and menopauseassociated changes in body fat distribution. Am f Clin Nutr 1992;55:950-4.

19 Ogino K, Osaki S, Kitamura H, et al. Ammonia response to exercise in patients with chronic heart failure. Heart 1996; 75:343-8.

20 Baron AD. Hemodynamic actions of insulin. Am f Physiol 1994;267:E187-202.

21 Lindsay D, Holdright DR, Clarke D, et al. Endothelial control of lower limb blood flow in chronic heart failure. Heart 1996;75:469-76. 
22 Sullivan MJ, Knight JD, Higginbotham MB, et al. Relation between central and peripheral hemodynamics during exercise in patients with chronic heart failure. Muscle blood flow is reduced with maintenance of arterial perfusion pressure. Circulation 1989;80:769-81.

23 Zelis R, Mason DT, Braunwald E. A comparison of the effects of vasodilator stimuli on peripheral resistance vessels in normal subjects and in patients with congestive heart failure. $\mathcal{F}$ Clin Invest 1968;47:960-70.
24 LeJemtel TH, Maskin CS, Lucido D, et al. Failure to augment maximal limb blood flow in response to one-leg versus two-leg exercise in patients with severe heart failure. Circulation 1986;74:245-51.

25 Sullivan MJ, Green HJ, Cobb FR. Skeletal muscle biochemistry and histology in ambulatory patients with long-term heart failure. Circulation 1990;81:518-27.

26 Paternostro G, Pagano D, Bonser RS, et al. The GLU-4 glucose transporter protein is reduced in the failing human heart [abstract]. Circulation 1997;96:I-627.

\section{IMAGES IN CARDIOLOGY}

\section{Covered stent to treat co-existent coarctation and aneurysm of the aorta in a young man}

A 23 year old man presented with hypertension and clinical, electrocardiographic, echocardiographic, and radiographic features of coarctation. Aortography delineated the coarctation (gradient $40 \mathrm{~mm} \mathrm{Hg}$ ) and a spherical aneurysm $3 \mathrm{~cm}$ across, originating at the coarctation. Under general anaesthesia, a cut-down

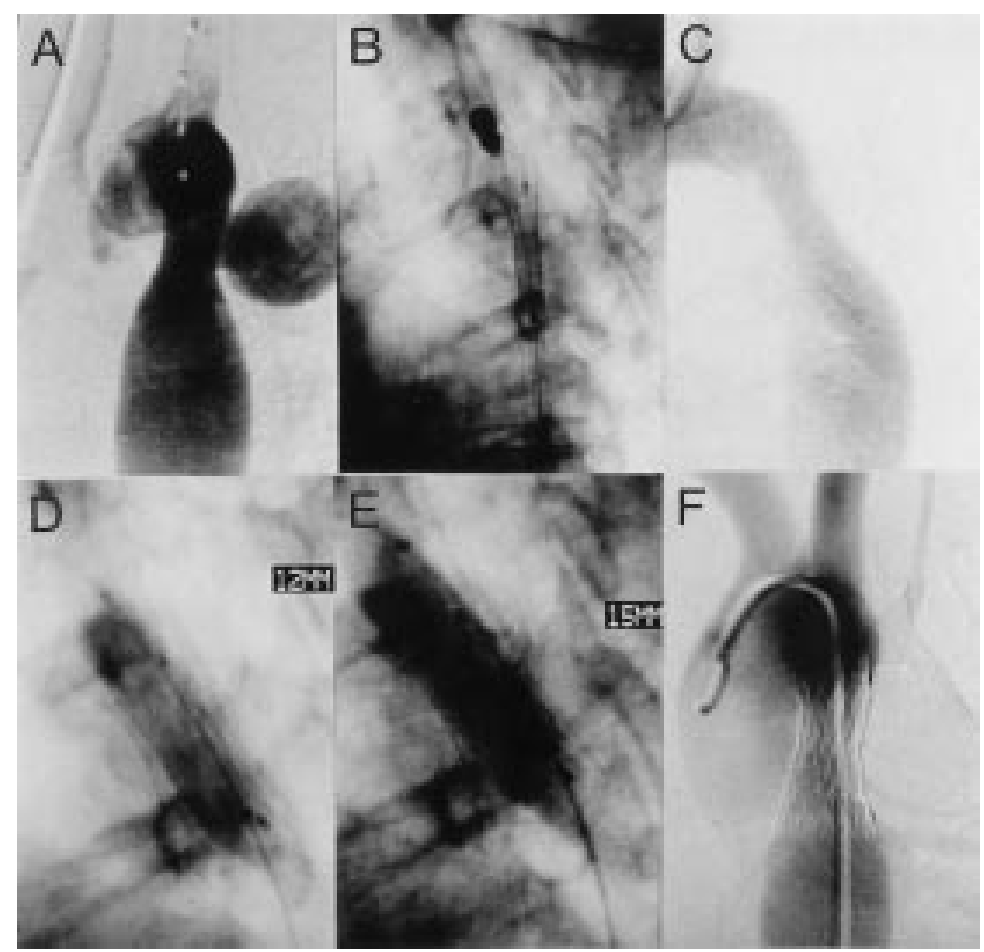

and femoral arteriotomy was made and a $16 \mathrm{~F}$ sheath inserted. A superstiff Amplatz 0.035 inch guidewire was advanced across the coarctation. A $37.5 \mathrm{~mm}$ long (maximum diameter $22 \mathrm{~mm}$ ) AneuRx (Medtronic, Watford, UK) self expanding, Nitinol mesh stent, covered with a stretchable polytetrafluoroethane membrane, was placed across both the coarctation and the neck of the aneurysm under fluoroscopic guidance. Serial dilatation was made with $12 \times 40 \mathrm{~mm}$ and $15 \times 40 \mathrm{~mm}$ balloons (Cordis, Ascot, UK). Balloon dilatation alone was rejected because of the danger of rupture of the aneurysm. A conventional, uncovered stent might have "splinted open" a dissection plane or failed to seal off the aneurysm. With the covered stent, care had to be taken to avoid the left subclavian artery, thereby avoiding any danger of embolising the vertebral circulation. The flexible nature of this stent graft, in contrast to slotted tube designs, suited the curve of the aorta. The final appearance of the stented segment was smooth and patent, with a minimal residual pressure gradient and exclusion of the aneurysm. The temptation to pursue an angiographically wider lumen was resisted because the gradient had been largely abolished and because of the risk of graft rupture. Computed tomography 24 hours later confirmed persisting exclusion of the aneurysm. Six months later, the patient was well with a blood pressure of $120 / 80 \mathrm{~mm} \mathrm{Hg}$.

JULIAN GUNN TREVOR CLEVELAND PETER GAINES 